\title{
COMMENTARY
}

\section{Is faster still better in therapeutic hypothermia?}

\author{
Daniel Howes* and David W Messenger \\ See related research by Haugk et al., http://ccforum.com/content/15/2/R101
}

\begin{abstract}
The rapid institution of therapeutic hypothermia after cardiac arrest has become an accepted practice. In the previous issue of Critical Care, Haugk and colleagues present a retrospective analysis of 13 years of experience with therapeutic hypothermia at their center that suggests an association between rate of cooling and less favorable neurological outcomes. The association most likely reflects easier cooling in patients more severely brain injured by their initial cardiac arrest, and should not lead clinicians to abandon or slow their efforts to achieve postresuscitative cooling.
\end{abstract}

Conscientious clinicians will always be challenged when they try to translate the latest research into good clinical practice. It can be particularly frustrating to hear that your efforts might in fact be harmful.

In the previous issue of Critical Care, Haugk and colleagues [1] report a retrospective analysis of 13 years of therapeutic hypothermia (TH) cases, suggesting a surprising association between faster rates of cooling and less favorable neurological outcomes. Their data generate some fascinating hypotheses and opportunities for future research but clinicians would be ill-advised, based on both our understanding of pathophysiology and the growing body of published evidence, to use this study as justification to relax efforts to achieve target temperatures as quickly as possible.

Precisely how TH improves neurological outcome after cardiac arrest is not known, but the mechanism is probably multi-factorial. $\mathrm{TH}$ is thought to minimize the release and the effect of free radicals, excitatory neurotransmitters and protease cascades during reperfusion of ischemic brain tissue, and may decrease vasoconstriction

\footnotetext{
*Correspondence: howesd@kgh.kari.net

Department of Emergency Medicine, Queen's University, Kingston, ON K7L 2V6, Canada
}

and intravascular thrombosis leading to potential ongoing micro-ischemia [2]. TH may also amplify the release of neuroprotective proteins [3]. For any of these proposed mechanisms, initiation of $\mathrm{TH}$ as soon as possible following resuscitation should be preferable.

Animal models that have been used to study TH have supported early, rapid cooling [4,5]. In fact, one of the greatest challenges of advancing animal research into the clinical realm has been the difficulty in matching the rapid induction methods achieved in the laboratory in human subjects, with the hopes of observing similar therapeutic benefits. Although no prospective, randomized clinical trials have assessed the effect of time to target temperature on neurological outcome, there are noteworthy signals from existing human trials that support a benefit to rapid cooling. Wolff and colleagues [6] analyzed patients rapidly cooled using an endovascular device and showed that the time to target temperature was an independent predictor for a good outcome (odds ratio 0.69 (0.51 to 0.98$)$ ). Although underpowered, recent clinical trials of rapid cooling devices have shown trends toward survival benefit [7] and improvement in patient outcomes compared to historical controls [8].

Retrospective data reviews are fraught with potential problems, and are best used to generate hypotheses for future rigorous prospective evaluation. Despite Haugk and colleagues' efforts to control for confounders statistically, their study does not demonstrate whether it is the rate of cooling or differences in other important variables influencing neurological outcome following $\mathrm{TH}$. At most, this study suggests a statistical association, but there is not sufficient biological plausibility to suggest a causal relationship. As the authors point out, their findings might well imply that greater neurological injury is predicted by more rapid achievement of cooling during $\mathrm{TH}$, rather than rapid cooling itself being inherently harmful. There is a plausible argument to be made that patients with more severe anoxic injury may be easier to cool to target temperature quickly because of damage of the thermoregulatory areas of the brain. In Haugk and colleagues' population, the starting temperatures in patients with poor neurological outcomes were half a degree lower before $\mathrm{TH}$ was started, suggesting that 
these patients were already showing some degree of impaired thermoregulation.

Researchers addressing the timing of $\mathrm{TH}$ induction face a difficult challenge - to separate the issues of time from return-of-spontaneous-circulation to target temperature, rate of cooling, and impaired thermoregulation. This will no doubt take place in a population that will vary in time to presentation for cooling and patient factors that affect the rate of cooling. There have been tremendous advancements in the methods available to cool patients quickly; cooling rates were originally in the area of $0.32^{\circ} \mathrm{C}$ per hour but we can now achieve rates more than ten-times faster [8] and are in a position to question how best to cool our patients.

It is time for researchers to ask and answer these challenging questions. Until then, clinicians should continue in their efforts to cool patients post-cardiac arrest as quickly as possible.

\section{Abbreviations}

$\mathrm{TH}$, therapeutic hypothermia.

\section{Competing interests}

DH participated in a research trial funded by Life Recovery Systems.

DWM declares that he has no competing interests.

\section{Author's information}

$\mathrm{DH}$ is an Associate Professor in the Department of Emergency Medicine at Queen's University and Program Director of the Critical Care training program. $\mathrm{He}$ is the Director of the Regional Trauma Program, Medical Director of the Kingston Resuscitation Institute at Queen's University and the Fellowship in Resuscitation medicine. DWM is an Assistant Professor in the Department of Emergency Medicine and the Critical Care Program at Queen's University, and serves on the Board of Directors for the Kingston Resuscitation Institute.

\section{Acknowledgements}

This manuscript was not funded.

Published: 1 June 2011

\section{References}

1. Haugk M, Testori C, Sterz F, Uranitsch M, Holzer M, Behringer W, Herkner H: Relationship between time to target temperature and outcome in patients treated with therapeutic hypothermia after cardiac arrest. Crit Care 2011, 15:R101.

2. Nolan, JP, Neumar RW, Adrie C, Aibiki M, Berg RA, Bottiger BW, CallawayC, Clark RSB, Geocadin RG, Jauch EC, Kern KB, Laurent I, Longstreth WT, Merchant RM, MorleyP, Morrison LJ, Madkarni V, Peberdy MA, Rivers EP, Rodriguez-Nunez A, Sellke FW, Spaulding C, Sunde K, Vanden Hoek T: Postcardiac arrest syndrome: epidemiology, pathophysiology, treatment, and prognostication A scientific statement from the international liaison committee on resuscitation; the American heart association emergency cardiovascular care committee; the council on cardiovascular surgery and anesthesia, the council on cardiopulmonary, perioperative and critical care, the council on clinical cardiology; the council on stroke. Resuscitation 2008, 79:350-379.

3. White C, Marcheselli VL, Janata A, Schratter A, Weihs W, Bayegan K, Milani RV, Bazan NG: Lipid mediators as novel biomarkers and surrogate indicators of neurologic recovery after cardiac arrest in a hypothermic swine model. Circulation 2006 114:|l 1203.

4. Kazutoshi K, Safar P, Radovsky A, Tisherman SA, Stezoski SW, Alexander H: Delay in cooling negates the beneficial effect of mild resuscitative cerebral hypothermia after cardiac arrest in dogs: a prospective, randomized study. Crit Care Med 1993, 21:1348-1358.

5. Noguchi K, Matsumoto N, Shiozaki T, Tasaki O, Ogura H, Kuwagata Y, Sugimoto $\mathrm{H}$, Seiyama A: Effects of timing and duration of hypothermia on survival in an experimental gerbil model of global ischemia. Resuscitation 2011, 82:481-486.

6. Wolff B, Machill K, Schumacher D, Schulzki I, Wener D: Early achievement of mild therapeutic hypothermia and the neurologic outcome after cardiac arrest. Int J Cardiol 2009, 133:223-228.

7. Castrén M, Nordberg P, Svensson L, Taccone F, Vincent J, Desruelles D, Eichwede F, Mols P, Schwab T, Vergnion M, Storm C, Pesenti A, Pachl J, Guérisse F, Elste T, Roessler M, Fritz H, Durnez P, Busch H, Inderbitzen B, Barbut D: Intra-arrest transnasal evaporative cooling. A randomized, prehospital, multicenter study (PRINCE: Pre-ROSC IntraNasal Cooling Effectiveness. Circulation 2010, 122:729-736.

8. Howes D, Ohley W, Dorian P, Klock C, Freedman R, Schock R, Krizanac D, Holzer M: Rapid induction of therapeutic hypothermia using convectiveimmersion surface cooling: Safety, efficacy and outcomes. Resuscitation 2010, 81:388-392.

doi:10.1186/cc10234

Cite this article as: Howes D, Messenger DW: Is faster still better in therapeutic hypothermia? Critical Care 2011, 15:162. 